\title{
EFFECT OF COOLING RATES ON THE WELD HEAT AFFECTED ZONE COARSE GRAIN MICROSTRUCTURE
}

\author{
Roman Celin*, Jaka Burja \\ Institute of Metals and Technology, Lepi pot 11, \\ 1000 Ljubljana, Slovenia
}

Received 02.03.2018

Accepted 30.03.2018

\begin{abstract}
The effect of a cooling rate on the S690Q quenched and tempered steel welded joint coarse grain heat affected zone microstructure was investigated using a dilatometer with controlled heating and cooling fixture. Steel samples were heated to a peak temperature of $1350{ }^{\circ} \mathrm{C}$ and cooled at the different cooling time $\Delta t_{8 / 5}$. A dilatometric analysis and hardness measurements of the simulated thermal cycle coarse grain samples were done. Transformation start and finish temperature were determined using dilatation vs. temperature data analysis. The microstructure of the sample with a cooling time $5 \mathrm{~s}$ consists of martensite, whereas at cooling time $80 \mathrm{~s}$ a bainitic microstructure was observed. The investigated steel cooling cycle using simulation approach makes possible to determine the range of an optimum CG HAZ cooling time for the welding.
\end{abstract}

Keywords: cooling rate; microstructure; martensite; bainite.

\section{Introduction}

The quenched and tempered low-alloy steels, usually contain less than $0.25 \%$ carbon and less than 5\% of alloying elements. Quenching and tempering strengthen these steels to produce microstructures containing martensite and bainite [1] and to increase of mechanical resistance giving rise to a proportional reduction of weight. As supplied quenched and tempered steel plate typically has a structure of well-tempered martensite/bainite. One of such steel grade is S690Q with a minimum yield strength of $690 \mathrm{MPa}$ and hardness higher than about $220 \mathrm{HV}$.

Standard welding techniques can be used for the welding quenched and tempered steel $[2,3,4]$. One of the influential parameters on the mechanical properties and microstructure of the welded joint is heat input [5]. To, Using the cooling time of $\Delta t_{8 / 5}$ will determine heat flow or cooling rate. The cooling time is defined as the time for the

\footnotetext{
* Corresponding author: Roman Celin, roman.celin@imt.si
} 
temperature dropping from $800{ }^{\circ} \mathrm{C}$ to $500{ }^{\circ} \mathrm{C}$ and is in inverse relation to the cooling rate $\left({ }^{\circ} \mathrm{C} / \mathrm{s}\right)$.

During welding, the temperature in the weld coarse grained heat affected zone (CG HAZ) can reach above $1100{ }^{\circ} \mathrm{C}$ [6]. Heat input and consequential CG zone decrease the weld toughness [7]. Due to high temperature, the initial tempered martensite microstructure of the as delivered steel undergoes austenite transformation into a CG HAZ. The grain growth, however, is retarded to some extent by the $\mathrm{V}(\mathrm{C}, \mathrm{N})$ precipitate pinning effect, but unfortunately, vanadium precipitates dissolve quickly above $\mathrm{Ac}_{3}$ [8, 9] If the cooling rate is high enough, martensitic or bainitic transformations from austenite take place, or both [10]. In the absence of post-weld heat treatment microstructure of the single pass weld HAZ is effectively un-tempered.

Weld cooling rates that are too high because of inappropriate welding parameters (low welding heat input) can result in HAZ hardening, while too high inter-pass temperature during welding in conjunction with high heat input can lead to softening of the HAZ [3]. This heat input narrows the cooling rate selection.

The CG HAZ region of the weld joint is narrow in relation to the weld. Welding thermal cycle simulation is used to achieve large volume of CG HAZ uniform microstructure suitable for investigations. Usually, thermal weld simulations are done in conjunction with weldability investigations to determine proper welding parameters $[4,11]$.

This work aimed to obtain the cooling time range used for the welding procedure, by application of thermal weld CG HAZ simulation and the corresponding microstructure analysis.

\section{EXPERIMENTAL PART}

The investigated S690Q steel plate was supplied in quenched and tempered condition. A quantitative chemical analysis of the steel sample was done with an ICP spectrometer. The chemical composition in weight $\%$ was: $0.162 \% \mathrm{C}, 0.28 \% \mathrm{Si}$, $0.71 \% \mathrm{Mn}, 0.53 \% \mathrm{Cr}, 0.24 \% \mathrm{Mo}, 0.19 \% \mathrm{Ni}, 0.05 \% \mathrm{~V}, 0.25 \% \mathrm{Cu}$ and $0.036 \% \mathrm{Al}$.

Five $10 \mathrm{~mm}$ long cylindrical samples with a $4 \mathrm{~mm}$ outer diameter were machined from as received $15 \mathrm{~mm} \mathrm{S690} \mathrm{Q} \mathrm{steel} \mathrm{plate.} \mathrm{Simulations} \mathrm{were} \mathrm{carried} \mathrm{out}$ with the DIL805A/D dilatometer in an argon atmosphere. Control of continuous cooling was maintained via type $\mathrm{S}$ thermocouple spot welded directly to the cylindrical sample.

Samples were heated to the peak temperature at the heating rate of $200{ }^{\circ} \mathrm{C} / \mathrm{s}$, held at the peak temperature of $1350{ }^{\circ} \mathrm{C}$ for $3 \mathrm{~s}$ (Figure 1) and then cooled with 5 different cooling times $\Delta t_{8 / 5}$ ranging from $5 \mathrm{~s}$ to $80 \mathrm{~s}$. The cooling cycle data acquisition was turned off at the $200{ }^{\circ} \mathrm{C}$. The peak temperature of $1350{ }^{\circ} \mathrm{C}$ was selected based on previous work [12]. 


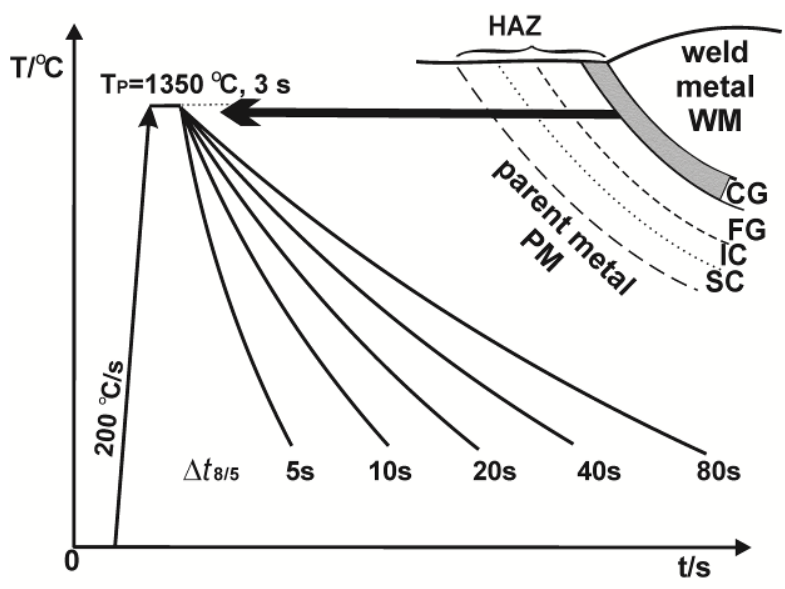

Fig. 1. Cooling cycles used with different $\Delta t_{8 / 5}$ times.

A dilatation data generated during cooling were recorded, and phase transformation points were obtained with the principle of tangent application. Preparation of specimen was done by grinding and polishing, followed by the chemical etching with the $3 \%$ Nital solution.

The microstructure of simulated specimens was observed with an optical microscope (OM) and scanning electron microscope (SEM).

Hardness HV5, on the specimens from the thermal cycle simulations, was measured by EN ISO 6507-1. Results of hardness testing were used to plot "Time $\Delta t_{8 / 5}$ vs. Hardness HV5" graph for the simulated CG HAZ microstructure.

\section{Results and discussion}

The dilatometric data at different cooling times were analyzed. A dilatation plots for samples obtained at $\Delta t_{8 / 5}$ cooling time $5 \mathrm{~s}, 20 \mathrm{~s}$, and $80 \mathrm{~s}$ is shown in Figure 2.

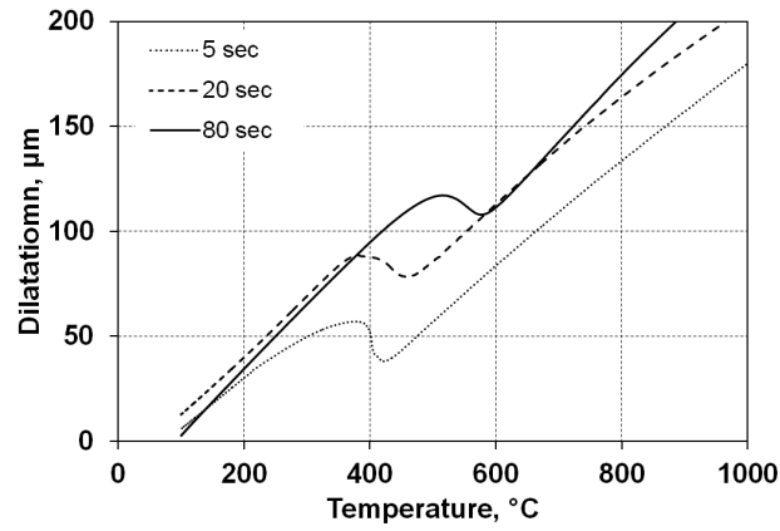

Fig. 2. Dilatation vs. temperature cooling curve of the CG HAZ specimens. 
During cooling, dilation of the sample decreases linearly from $1350{ }^{\circ} \mathrm{C}$ with the decrease in temperature until it reaches transformation start temperature. There is a beginning of a change in phase from more densely packed austenite face-centered cubic (fcc) to the less densely packed crystal structures of either body-centered cubic (bcc) ferrite or body-centered tetragonal (bct) martensite. This change in packing density results in an increase in the length of the sample. Dilatation again decreases linearly due to thermal contraction.

Based on the dilatometric data cooling diagram for simulated weld CG HAZ microstructure was constructed and is shown in Figure 3. Due to a limited range of the cooling rates and to the low carbon content in the given steel, only the transformation start and transformation finish temperatures were determined on the dilatation curves.

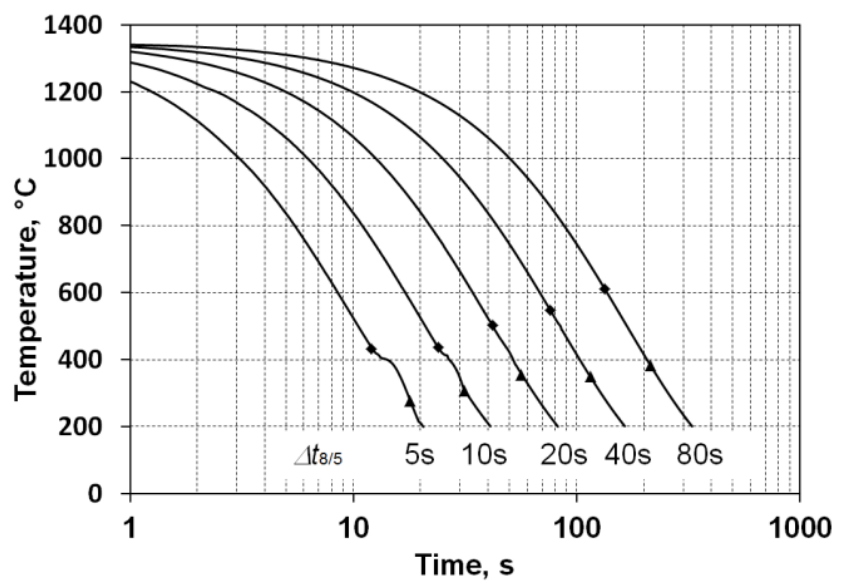

Fig. 3. Cooling diagram of the simulated weld CG HAZ samples.

From the Figure 3 can be noted that the transformation start and transformation finish temperatures gradually rise with increasing cooling time $\Delta t_{8 / 5}$.

\section{Microstructure}

Typical microstructures of base metal (BM) and simulated CG HAZ obtained in tests with different cooling times are shown in Figure 4. The microstructure of the base metal mainly consists of tempered martensite and a small amount of lower bainite (Figure $4 \mathrm{a}$ and $5 \mathrm{a}$ ). The microstructure in Figure $4 \mathrm{~b}$ and $5 \mathrm{~b}$ with the shortest cooling time of the $5 \mathrm{~s}$, is coarse-grained and exhibits a martensitic morphology. With increasing cooling time $\Delta t_{8 / 5}$ a mixture of martensite and bainite is formed (Figure $4 \mathrm{c}$ and $5 \mathrm{c}$ ). At the cooling time of the $80 \mathrm{~s}$ (Figure $4 \mathrm{~d}$ and 5d), a fine-grained bainitic microstructure appears. 

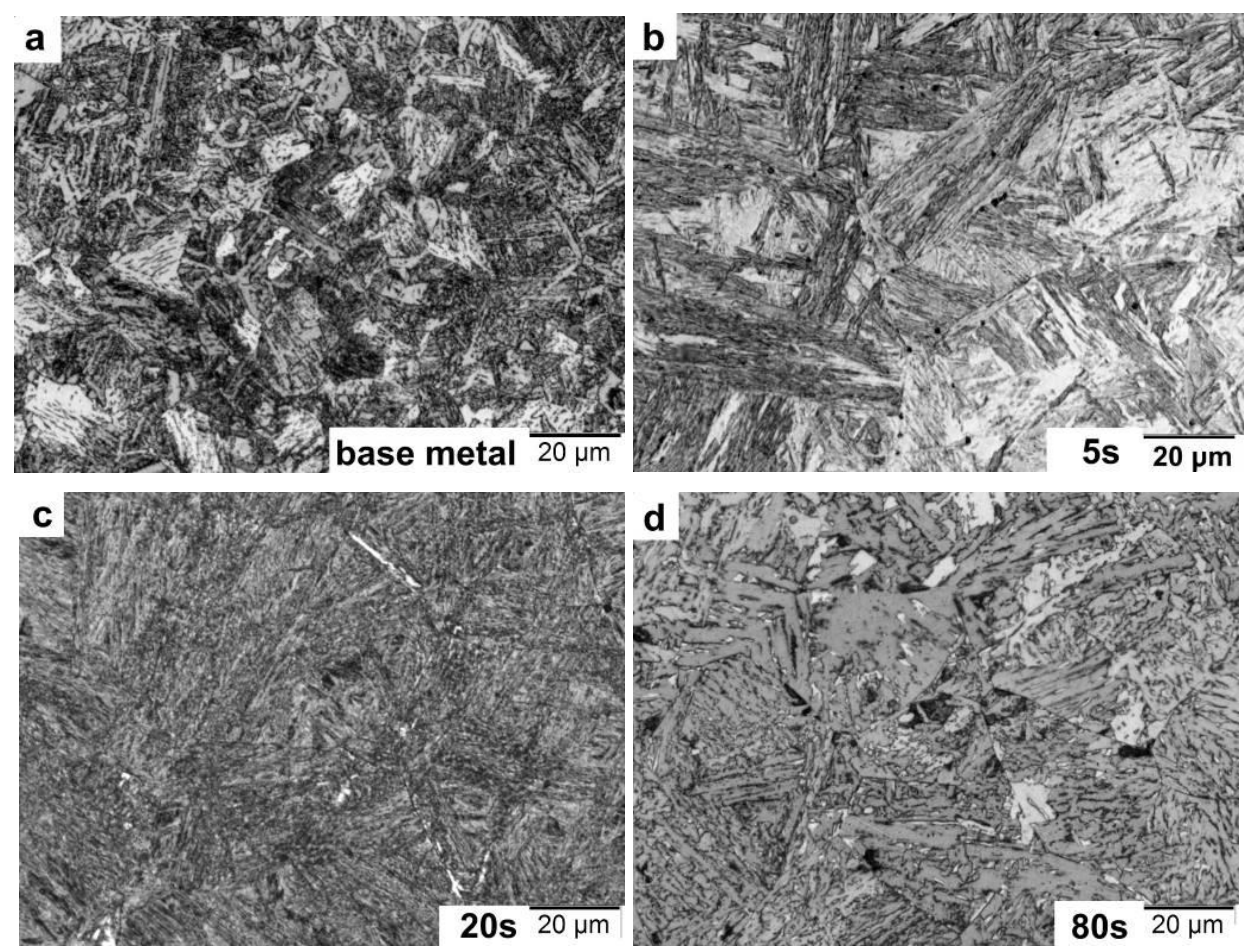

Fig. 4. Optical micrographs of base metal and simulated CG HAZ samples at different cooling times.
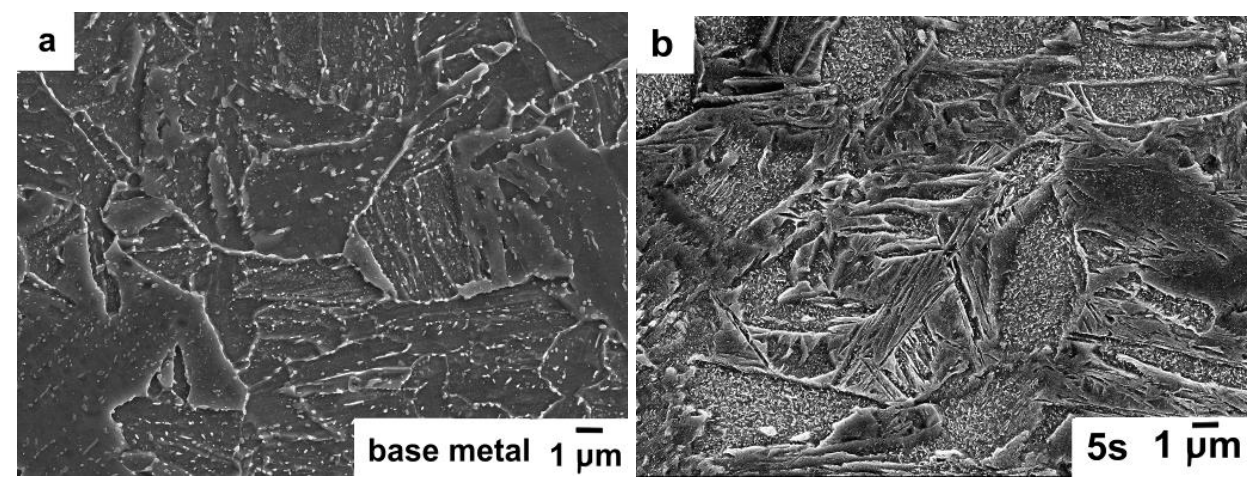

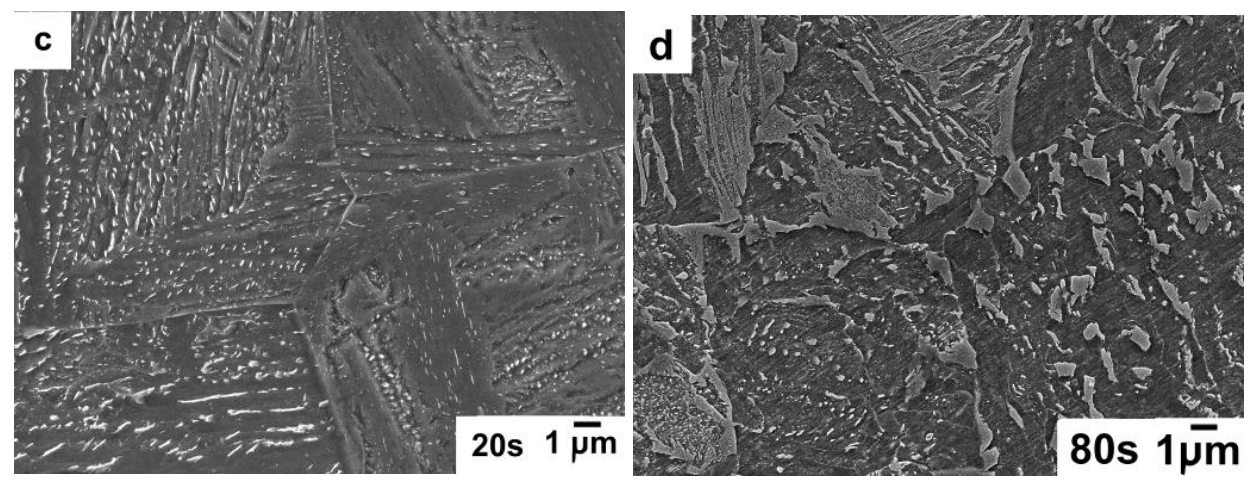

Fig. 5. SEM images of base metal and simulated CG HAZ samples at different cooling times.

Under a light microscope, it can be difficult to accurately distinguish the microstructure of the martensite and bainite due to their shared shearing mechanism. The difference between the two can be confirmed by the Vickers hardness measurement (Figure 6).

\section{Hardness}

The corresponding variation of simulated CG HAZ HV5 hardness versus the cooling time $\Delta t_{8 / 5}$ for the investigated steel is given in Figure 6 . The average hardness of the as delivered S690Q steel (base metal) was 250 HV5. The highest value of hardness 472 HV5 is due to martensite microstructure, consequent upon the high cooling rate $\left(\Delta t_{8 / 5}=5 \mathrm{~s}\right)$. At high cooling rates formation of martensite is enhanced by the shear displacement of iron atoms into an interstitial, supersaturated solid solution of iron and carbon. This displacement results in lattice distortion which provides strength and hardness by obstructing dislocation movements. Higher material hardness and strength, existing vulnerability to hydrogen embrittlement [13]. CG HAZ is usually even more susceptible to hydrogen embrittlement [14]. As the cooling time $\Delta t_{8 / 5}$ increases, the cooling rate becomes slower, and hardness decreases. At the same time, the microstructure changes to the mixture of martensite and bainite. Hardness decreases further from $445 \mathrm{HV} 5$ at $\Delta \mathrm{t} 8 / 5=10 \mathrm{~s}$ to $338 \mathrm{HV} 5$ at $\Delta \mathrm{t} 8 / 5=40 \mathrm{~s}$ with the diminishing volume fraction of martensite and increasing the formation of bainite (265 HV5 at $\Delta t_{8 / 5}=80 \mathrm{~s}$ ). The results suggest that CG HAZ hardness tends towards the base metal hardness when $\Delta t_{8 / 5}$ cooling time is greater than $80 \mathrm{~s}$. 


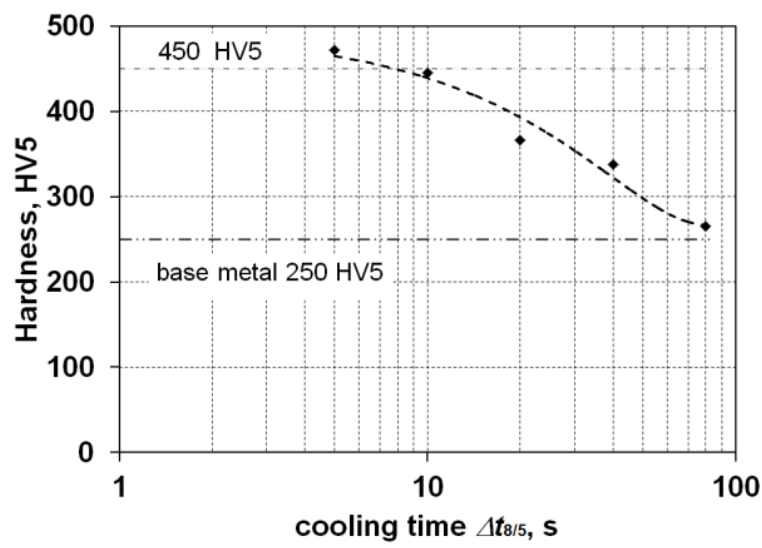

Fig. 6. Simulated CG HAZ HV5 hardness variation

\section{Conclusions}

The present work describes a simplified approach to the prediction of CG HAZ hardness and microstructural characteristics in quenched and tempered welded steel. The main conclusions of this investigation are:

1) The use of dilatometer and cooling cycle simulation makes it possible to predict CG HAZ microstructure and hardness as the first step in material weldability study.

2) The microstructure of simulated CG HAZ changes from martensite formed at the highest cooling rate to bainite formed at the lowest cooling rate.

3) An apparent decrease in HV5 hardness accompanies a change in a microstructure.

4) An investigation results suggest that CG HAZ $\Delta t_{8 / 5}$ should be limited to $10 \mathrm{~s}$ and $30 \mathrm{~s}$. Welding parameters should be chosen accordingly.

5) Due to the high HV5 value of the simulated CG HAZ samples, during real welding care must be taken to reduce the hydrogen content in the weld joint to avoid the possibility of hydrogen cracking.

\section{References}

[1] Winsor, F. J., in ASM Handbook, Vol. 6: Welding, Brazing and Soldering, ASM International, Materials Park, OH, 1993, p. 662.

[2] S. Błacha, M.St. Węglowski, S. Dymek, M. Kopuściański: Arch metall mater, 61 (2016) 1193-1200.

[3] L. Zhang, T. Kannengiesser: Weld World, 60 (2016) 177-184.

[4] V. G. Haugen, B. R. S. Rogne, O. M. Akselsen, C. Thaulow, E. Østby: Materials and Design, 59 (2014) 135-140.

[5] H. Dong, X. Hao, D. Deng: Metallogr Microstruct Anal, 3 (2014) 138-146.

[6] I. Hajro, O. Pašić, Z. Burzić: Zavarivanje i zavarene konstrukcije, 58 (2010) 123 129.

[7] A. Kurc-Lisiecka and A. Lisiecki, Mater Tehnol, 51 (2017) 199-204. 
[8] A. G. Kostryzhev, E. U. Morales-Cruz, J. Zuno-Silva, E. Cardoso-Legorreta, I. Ruiz-Lopez, E. V. Pereloma: Steel Res Int, 88 (2017) 1-11.

[9] S. Medina, I. Ruiz-Bustinza, J. Robla, J. Calvo: Metals (Basel) 7, 45 (2017)

[10] G. Kosec, J. Vojvodič Tuma, M. Gojič, A. Nagode, A, Stoić, I. Samardžić, B. Kosec: Tehnički vjesnik, 23 (2016) 761-767.

[11] Z. Zhu, L. Kuzmikova, H. Li, F. Barbaro: Materials Science \& Engineering, A 605 (2014) 8-13.

[12] R. Celin, J. Burja, G. Kosec: Materials and technology 50 (2016) 455-460.

[13] M. Koyama, E. Akiyama, Y. K. Lee, D. Raabe, K. Tsuzaki: Int J Hydrogen Energy 42, (2017) 12706-12723.

[14] T. Zhang, W. Zhao, Q. Deng, W. Jiang, Y. Wang, Y. Wang, W. Jiang: Int J Hydrogen Energy, 42 (2017) 25102-25113.

\section{(c) (7) Creative Commons License}

This work is licensed under a Creative Commons Attribution 4.0 International License. 